\title{
Medication errors among Iranian emergency nurses: a systematic review
}

\author{
Zohreh Hosseini Marznaki', Somaye Pouy², Waliu Jawula Salisu³, Amir Emami Zeydi ${ }^{4}$ \\ 'Department of Nursing, Amol Faculty of Nursing and Midwifery, Mazandaran University of Medical Sciences, Sari, Iran; ${ }^{2}$ Student Research \\ Committee, School of Nursing and Midwifery, Guilan University of Medical Sciences, Rasht, Iran; ${ }^{3}$ Department of Nursing, Tamale Teaching \\ Hospital, Tamale, Ghana; ${ }^{4}$ Department of Medical-Surgical Nursing, Nasibeh School of Nursing and Midwifery, Mazandaran University of \\ Medical Sciences, Sari, Iran
}

OBJECTIVES: Medication errors (MEs) made by nurses are the most common errors in emergency departments (EDs). Identifying the factors responsible for MEs is crucial in designing optimal strategies for reducing such occurrences. The present study aimed to review the literature describing the prevalence and factors affecting MEs among emergency ward nurses in Iran.

METHODS: We searched electronic databases, including the Scientific Information Database, PubMed, Cochrane Library, Web of Science, Scopus, and Google Scholar, for scientific studies conducted among emergency ward nurses in Iran. The studies were restricted to full-text, peer-reviewed studies published from inception to December 2019, in the Persian and English languages, that evaluated MEs among emergency ward nurses in Iran.

RESULTS: Eight studies met the inclusion criteria. Most of the nurses (58.9\%) had committed MEs only once. The overall mean rate of MEs was $46.2 \%$, and errors made during drug administration accounted for $41.7 \%$ of MEs. The most common type of administration error was drug omission (17.8\%), followed by administering drugs at the wrong time (17.5\%) and at an incorrect dosage (10.6\%). The lack of an adequate nursing workforce during shifts and improper nurse-patient ratios were the most critical factors affecting the occurrence of MEs by nurses.

CONCLUSIONS: Despite the increased attention on patient safety in Iran, MEs by nurses remain a significant concern in EDs. Therefore, nurse managers and policy-makers must take adequate measures to reduce the incidence of MEs and their potential negative consequences.

KEY WORDS: Medication errors, Nurse, Emergency service, Hospital, Iran

\section{INTRODUCTION}

Patient safety is a critical component of the healthcare system [1], but may be hindered by several factors, including medication

\section{Correspondence: Amir Emami Zeydi}

Department of Medical-Surgical Nursing, Nasibeh School of Nursing and Midwifery, Vesal Street, Amir Mazandarani Boulevard, Sari 4816715793, Iran

E-mail: emamizeydi@yahoo.com

Received: Mar 29, 2020 / Accepted: May 13, 2020 / Published: May 13, 2020

This article is available from: https://e-epih.org/

(c) This is an open-access article distributed under the terms of the Creative Commons Attribution License (https://creativecommons.org/licenses/by/4.0/), which permits unrestricted use, distribution, and reproduction in any medium, provided the original work is properly cited.

(C) 2020, Korean Society of Epidemiology errors (MEs), which are among the most common mistakes that threaten patient safety [2]. Although MEs occur with substantial frequency in hospital environments, they are significantly more common in units with more severely ill patients, such as the emergency department (ED), with rates ranging from $4 \%$ to $68 \%$ [3-6]. The unpredictability and complex nature of EDs, the critical situation of most patients, and the heavy workload due to inadequate patient-nurse ratios make the ED a high-risk area for MEs $[5,6]$.

Previous studies have suggested that most MEs made in EDs are by nurses, with higher frequencies during administration of drugs [7-9]. Nurses spend more time with patients than most other healthcare workers and play significant roles in the process of medication management and improving patient safety [10-13]. Therefore, identifying the pattern, prevalence, and factors associated with the occurrence of MEs in the EDs can help nurse man- 
agers to develop innovative, data-driven strategies to reduce the incidence of MEs and their negative consequences [14-17]. Despite the importance of MEs in EDs and the critical role of nurses in this regard [18], there is a lack of comprehensive data concerning the prevalence and associated factors of MEs among emergency ward nurses in Iran. Therefore, this study aimed to review the literature on this issue.

\section{MATERIALS AND METHODS}

\section{Search strategy}

In this current review, we conducted an electronic search of several databases, including the Scientific Information Database, PubMed, Cochrane Library, Web of Science, Scopus, and Google Scholar, from database inception until December 2019. The following keywords were used: "medication error," "prescribing error," "medication incidents," "medication administration error," "drug administration error," "drug error," "nurse," "emergency unit," "emergency room," "emergency ward," "emergency medical service," and "Iran." The languages of the studies were restricted to Persian and English. When searching the Persian electronic databases, the equivalents of the keywords in Persian were used. We excluded the gray literature because, in our opinion, research in the gray literature usually does not portray the whole picture of the results, and when fully published, the results may change substantially.

\section{Inclusion/exclusion criteria}

Full-text, peer-reviewed published studies that evaluated MEs among emergency ward nurses in Iran were included in this study. We excluded studies that were conducted among any other healthcare providers, or among nurses who worked in other, non-emergency wards. Reviews, letters, randomized controlled trials, case studies, conference papers, opinions, dissertations, reports, and editorial papers were excluded. We also excluded studies with no access to the full-text.

\section{Study selection}

After removing duplicate studies, 2 reviewers independently evaluated the titles, abstracts, and then the full-text of studies that were potentially eligible for this review. The references of included studies were manually checked to ensure that relevant studies were not omitted. Any disagreements between reviewers were resolved by discussion.
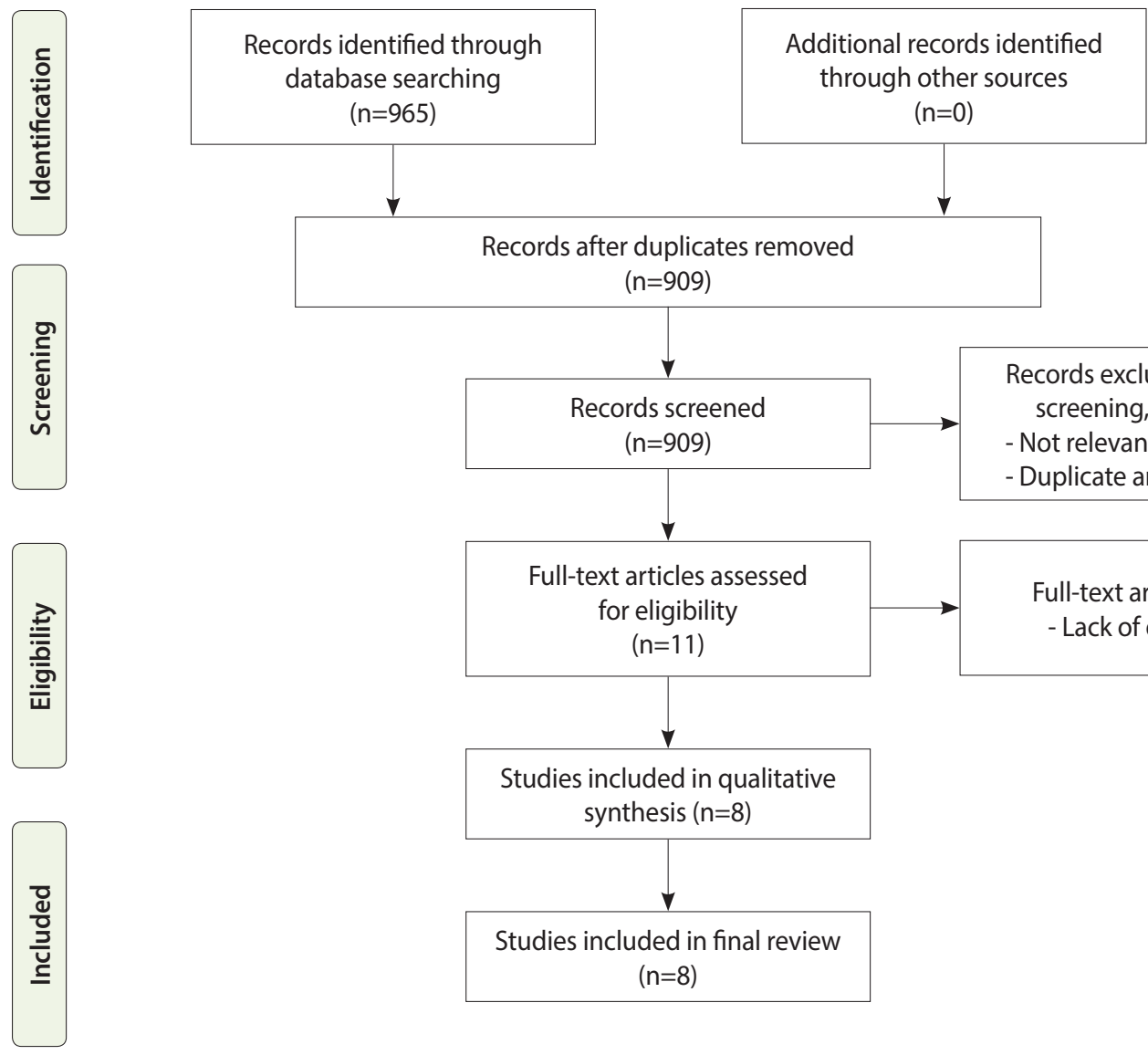

Records excluded after title/abstract screening, with reason $(n=898)$

- Not relevant to main topic $(n=878)$

- Duplicate article/data $(n=20)$

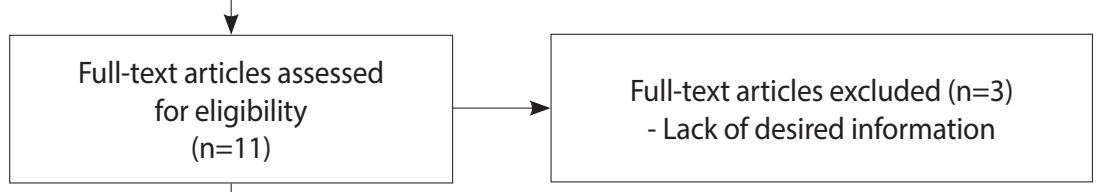

Figure 1. Flow diagram of the literature search. 


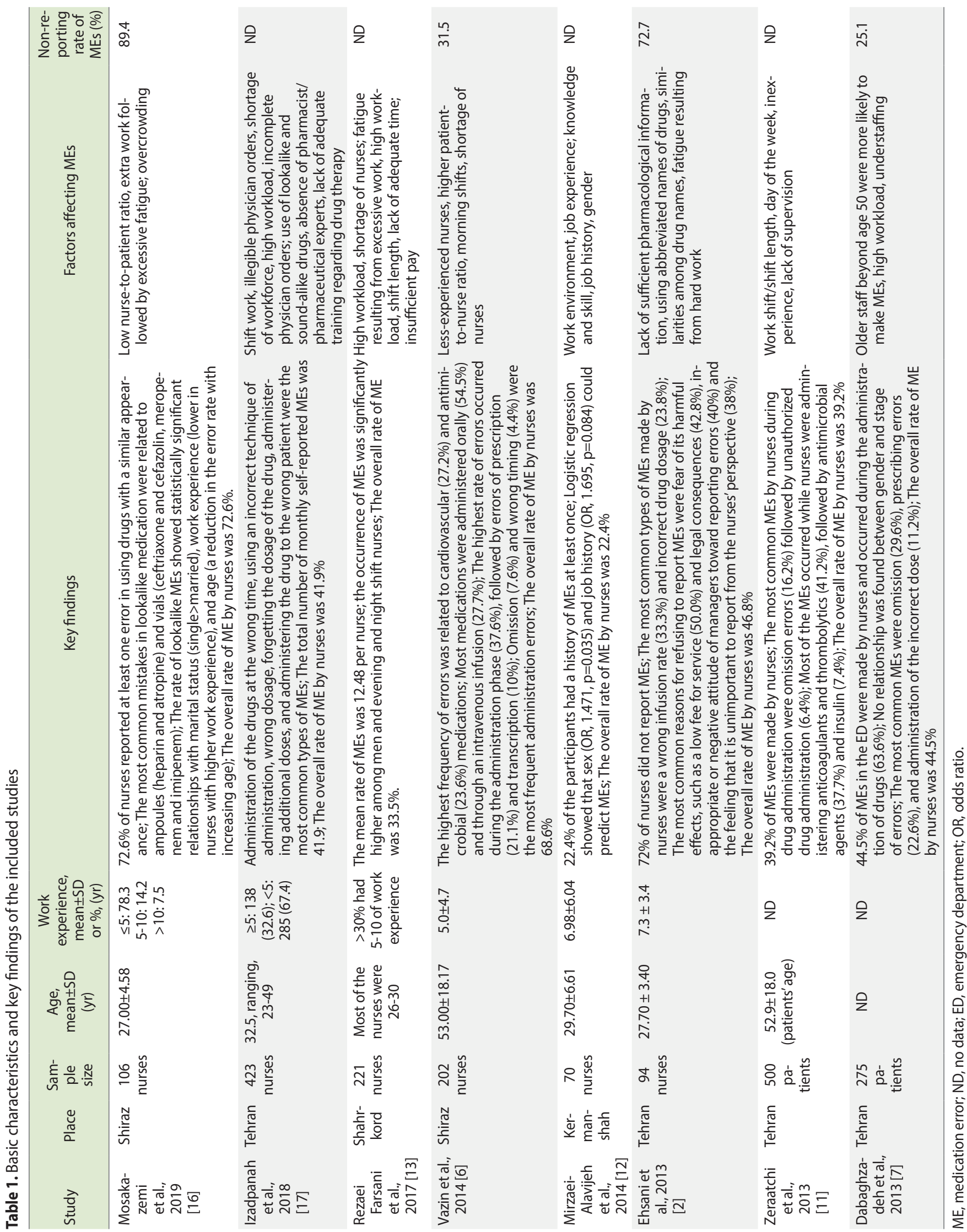




\section{Data extraction and quality assessment}

We designed a data extraction form to capture the following information from the included studies: name of the first author, year of the study, place of the study, sample size, age, work experience, key findings, factors affecting MEs, and the non-reporting rate of MEs by nurses. The British Sociological Association Medical Sociology Group appraisal tool was used to assess the methodological quality of the included studies [19]. Quality was categorized as high (score, 6-7), moderate (score, 3-5), or low (score, 1-2). Two independent reviewers carried out these procedures. Disagreements were resolved by discussion with a third author. To calculate the total prevalence of MEs, we used the simple mean of the sum of the ME rates and divided it by the total number of studies. We contacted the authors of included papers for additional related information if data provided were insufficient.

\section{Ethics statement}

As the present study was a systematic review, no ethics statement was needed.

\section{RESULTS}

\section{Study characteristics}

The literature search generated 909 articles, of which $901 \mathrm{did}$ not meet the inclusion criteria. The remaining 8 studies were finally included for further review (Figure 1). In total, 1,116 nurses were evaluated in the included studies, with a mean age of $32.24 \pm$ 6.21 years. The mean work experience of the nurses was $5.22 \pm 4.10$ years. Approximately $66.0 \%$ of the nurses were women, and $55.6 \%$ were married. According to the available data, most of the nurses had committed MEs only once (58.7\%), and the majority of nurses (91.4\%) having a bachelor's degree. Details of the included studies are shown in Table 1.

\section{Methodological quality of the included studies}

All the included studies used a cross-sectional design. The quality assessment of included studies indicated that $62.0 \%$ of the stud- ies were of high quality, and the other $38.0 \%$ were of moderate methodological quality (Table 2).

\section{Prevalence and types of medication errors}

The overall mean rate of self-reported MEs by Iranian emergency nurses was $46.2 \%$. According to available reported data, MEs were most commonly reported to occur during the drug administration stage, with a rate of $41.7 \%$. The most common type of administration error was a wrong infusion rate (33.3\%), followed by drug omission (17.8\%), administering drugs at the wrong time (17.5\%), an incorrect dosage (10.6\%) and improperly administering unauthorized medications $(6.4 \%)[2,14,18]$. Another form of an incorrect dosage involves an erroneous calculation of the dose. Anticoagulants and thrombolytic medications (41.2\%), antimicrobial agents (37.7\%), and insulin (7.4\%) were the most common drugs that were incorrectly administered [11]. Some lookalike MEs occurred among emergency nurses due to their similar names and pronunciations. For example, atropine and heparin, ceftriaxone and cefazolin, and meropenem and imipenem caused confusion. For fluids, confusion frequently occurred between normal saline and dextrose saline [16]. The non-reporting rate of MEs by emergency nurses is presented in Table 1 .

\section{Medication error-related adverse events}

Most of the included studies neither evaluated nor reported the clinical consequences of MEs and ME-related adverse events. However, 1 study stated that $97.5 \%$ of patients did not experience any critical adverse events caused by MEs made by nurses [2]

\section{Factors contributing to medication errors}

The lack of an adequate nursing workforce during shifts and inappropriate nurse-patient ratios $[6,11,16,17]$, as well as inadequate knowledge of medications before administering them to patients [2,16-18], accounted for the majority of reported cases of MEs made by emergency ward nurses in Iran. Demographic factors such as nurses' age, gender, and work experience have been reported to be closely related to the risk of MEs [11-13,17]. Other

Table 2. Methodological quality assessment of the included studies.

\begin{tabular}{|c|c|c|c|c|c|c|c|c|}
\hline \multirow{2}{*}{ Quality assessment } & \multicolumn{8}{|c|}{ Reference } \\
\hline & [13] & [17] & {$[16]$} & {$[6]$} & {$[12]$} & {$[2]$} & [11] & [7] \\
\hline 1. Appropriate research desigh $(\mathrm{Y} / \mathrm{N})$ & Y & $\mathrm{Y}$ & $\mathrm{Y}$ & Y & $\mathrm{Y}$ & Y & Y & $\mathrm{Y}$ \\
\hline 2. Appropriate recruitment strategy $(\mathrm{Y} / \mathrm{N})$ & $\mathrm{N}$ & $\mathrm{Y}$ & Y & Y & $\mathrm{Y}$ & Y & Y & $\mathrm{Y}$ \\
\hline 3. Response rate reported $(\mathrm{Y} / \mathrm{N})$ & $\mathrm{Y}$ & $\mathrm{Y}$ & Y & Y & $\mathrm{Y}$ & Y & Y & $\mathrm{Y}$ \\
\hline 4. Sample representative of similar population $(\mathrm{Y} / \mathrm{N})$ & $\mathrm{Y}$ & Y & $\mathrm{Y}$ & Y & $\mathrm{Y}$ & $\mathrm{Y}$ & Y & Y \\
\hline 5. Objective and reliable measures used $(\mathrm{Y} / \mathrm{N})$ & $\mathrm{N}$ & $\mathrm{N}$ & $\mathrm{N}$ & N & N & $\mathrm{N}$ & N & $\mathrm{N}$ \\
\hline 6. Power calculation/justification of numbers reported $(\mathrm{Y} / \mathrm{N})$ & $\mathrm{N}$ & $\mathrm{N}$ & $\mathrm{Y}$ & Y & $\mathrm{Y}$ & $\mathrm{Y}$ & Y & N \\
\hline 7. Appropriate statistical analysis ( $\mathrm{Y} / \mathrm{N})$ & $\mathrm{N}$ & Y & Y & Y & Y & Y & Y & Y \\
\hline Quality indicators met (out of 7) & 3 & 5 & 6 & 6 & 6 & 6 & 6 & 5 \\
\hline
\end{tabular}

Y, yes; N, no. 
factors, such as the busy nature of emergency wards $[7,16]$ and managerial lapses, were also responsible for MEs made by nurses in EDs $[14,18]$.

\section{DISCUSSION}

As one of the most significant problem in hospitals, MEs have a considerable negative impact on most countries' healthcare sectors [20-22]. MEs are responsible for the vast majority of iatrogenic injuries [23], prompting healthcare officials around the world to search for effective ways to minimize their occurrence $[8,24,25]$. Based on the results of the present study, the rate of drug administration errors was high (41.7\%). Similarly, a previous study reported that the overall rate of MEs in Iran ranged from $14.3 \%$ to $70.0 \%$ [26]. Errors such as incorrect timing, omissions, and wrong dosages are linked to inadequate staffing, which imposes a heavy work burden on nurses $[2,7,11,17,18,27]$. Work overload is known to lead to fatigue $[5,28]$, resulting in a loss of focus that consequently increases the likelihood of errors and adverse events [26,29]. We found that professional experience and education contributed significantly to reducing MEs. Nurses with higher work experience or adequate in-service training were less likely to commit MEs than less experienced nurses [30]. A study by Tang et al. [31] in Taiwan showed that nurses' inadequate training in the wards was associated with an increased risk of MEs. Another study conducted in Canada showed that insufficient training of the staff contributed to the incidence of MEs, although to a minor extent [32]. Indeed, training has direct advantages, such as augmenting nurses' level of knowledge and skills and improving the quality of nursing care through the application of the learned knowledge [33]. Thus, frequent in-service training for nurses is beneficial because it increases nurses' knowledge. Other forms of MEs, such as dispensing errors, which involve dispensing medications that vary from the written orders of prescribers [34], were less widely reported in the current study, primarily because in Iran, dispensing medications is the responsibility of the pharmacist. However, the rates of dispensing and prescribing errors among other health professionals in Iran have been documented elsewhere [26].

We found that the most frequent type of ME was improper administration of medications, including omissions. According to a study by Zeraatchi et al. [11], one of the main reasons for this type of error is the use of the traditional paper-based prescribing systems rather than computerized prescription systems. The former system makes it easy for nurses to misinterpret prescriptions and administer them incorrectly. To minimize this problem, many countries have adopted computerized medical record-keeping, drug compliance systems, bar code systems, drug dispensing systems, and smart pumps to enhance the safety of pharmaceutical processes [35]. Studies have also reported that the presence of clinical pharmacists in hospital wards is one of the best-proven solutions for reducing MEs [17,36]. Zarif-Yeganeh et al. [37] reported that clinical pharmacists in EDs provided accurate drug information and monitored drug distribution, leading to a reduced incidence of MEs. The multidisciplinary team approach proposed by the Agency for Healthcare Research and Quality could serve as a dependable and applicable framework. This approach involves engaging a multidisciplinary team including advanced practice providers, physicians, pharmacists, and nurses to improve medication administration practices and patient safety [38]. However, nurses must ensure that they adhere to the 5 basic "rights" at all times when administering medications: the right patient, the right drug, the right route, the right time, and the right medication. These are effective ways to minimize MEs [39].

Based on the results of this study, it is apparent that MEs by emergency nurses are common occurrences in Iran. However, many go unreported, as suggested by other researchers [18]. Previous studies have indicated that the non-reporting of MEs is mainly due to the fear of consequences, managerial issues such as bureaucracies, and the inappropriate response of managers $[26,40]$. The lack of accurate information on MEs in Iran could be a sign of a weakness in the system for reporting MEs [26]. Therefore, measures such as the implementation of supportive and non-punitive systems, along with regular training, will help medical staff understand that not reporting errors imposes more significant damages than reporting them [41]. Nurses must be well informed about what constitutes an error, how errors occur, which incidents should be reported, and clear-cut reporting channels [42]. With these measures in place, the rate of MEs could be reduced. Furthermore, managers and decision-makers in the field of nursing should provide appropriate conditions to reduce the incidence of MEs in EDs in Iran. For example, regular training should be organized for the nursing staff, while ensuring that the staffing level matches patient numbers. Doing so will reduce staff workload and fatigue, which are contributors to MEs. Regular training is recommended to keep nurses updated about new medications and drug-administration protocols [43]. Furthermore, nurse authorities and hospital managers should endeavor to established computerized prescribing systems in all hospital units [44]. Computerized systems are effective at carrying out orders and detecting errors, and are not susceptible to basic human shortfalls such as fatigue and forgetfulness [45]. Similarly, computerized systems perform adequate checks, and are effective countermeasures against errors resulting from prescribers' ineligible handwriting and confusions relating to similar drug names and unclear abbreviations [42]. A limitation of this study is that since it focused on a sensitive topic, the findings of some of the included studies might not have been fully accurate, because nurses may fear the negative consequences of reporting MEs, such as punishments, legal problems, and punitive organizational measures [46]. This possibility may have led to the misrepresentation of some aspects of the results presented herein.

\section{CONCLUSION}

Despite the increased attention on patient safety in Iran, MEs made by nurses remain a significant concern in EDs. Based on 
our findings, nearly half of the nurses who work in EDs in Iran have made MEs of some type during practice. Inappropriate nursepatient ratios and nurses' lack of adequate knowledge about medications are some of the critical factors responsible for MEs. Nurse managers and policy-makers must implement effective measures to reduce the incidence of MEs and its potential negative consequences.

\section{CONFLICT OF INTEREST}

The authors have no conflicts of interest to declare for this study.

\section{FUNDING}

None.

\section{ACKNOWLEDGEMENTS}

None.

\section{AUTHOR CONTRIBUTIONS}

Conceptualization: ZHM, AEZ. Data curation: ZHM, SP, WJS, AEZ. Formal analysis: ZHM, SP. Methodology: ZHM, AEZ. Project administration: ZHM, AEZ. Visualization: ZHM, AEZ. Writing - original draft: ZHM, SP, AEZ. Writing - review \& editing: ZHM, SP, WJS, AEZ.

\section{ORCID}

Zohreh Hosseini Marznaki: https://orcid.org/0000-0002-57761914; Somaye Pouy: https://orcid.org/0000-0003-3307-7840; Waliu Jawula Salisu: $h t t p s: / / o r c i d . o r g / 0000-0001-9725-4936$; Amir Emami Zeydi: https://orcid.org/0000-0001-8984-3298

\section{REFERENCES}

1. Acheampong F, Anto BP, Koffuor GA. Medication safety strategies in hospitals--a systematic review. Int J Risk Saf Med 2014; 26:117-131.

2. Ehsani SR, Cheraghi MA, Nejati A, Salari A, Esmaeilpoor AH, Nejad EM. Medication errors of nurses in the emergency department. J Med Ethics Hist Med 2013;6:11.

3. Hillin E, Hicks RW. Medication errors from an emergency room setting: safety solutions for nurses. Crit Care Nurs Clin North Am 2010;22:191-196.

4. Shitu Z, Aung MM, Tuan Kamauzaman TH, Ab Rahman AF. Prevalence and characteristics of medication errors at an emergency department of a teaching hospital in Malaysia. BMC Health Serv Res 2020;20:56.

5. Zarea K, Mohammadi A, Beiranvand S, Hassani F, Baraz S. Iranian nurses' medication errors: a survey of the types, the causes, and the related factors. Int J Afr Nurs Sci 2018;8:112-116.
6. Vazin A, Zamani Z, Hatam N. Frequency of medication errors in an emergency department of a large teaching hospital in southern Iran. Drug Healthc Patient Saf 2014;6:179-184.

7. Dabaghzadeh F, Rashidian A, Torkamandi H, Alahyari S, Hanafi S, Farsaei S, et al. Medication errors in an emergency department in a large teaching hospital in Tehran. Iran J Pharm Res 2013;12: 937-942.

8. Shahrokhi A, Ebrahimpour F, Ghodousi A. Factors effective on medication errors: a nursing view. J Res Pharm Pract 2013;2:1823.

9. Patanwala AE, Warholak TL, Sanders AB, Erstad BL. A prospective observational study of medication errors in a tertiary care emergency department. Ann Emerg Med 2010;55:522-526.

10. Rossetti AC, Gaidzinski RR, Fugulin FM. Nursing workload in the emergency department: a methodological proposal. Rev Lat Am Enfermagem 2013;21:225-232.

11. Zeraatchi A, Talebian MT, Nejati A, Dashti-Khavidaki S. Frequency and types of the medication errors in an academic emergency department in Iran: the emergent need for clinical pharmacy services in emergency departments. J Res Pharm Pract 2013; 2:118-122.

12. Mirzaei-Alavijeh M, Jalilian F, Karami-Matin B, Ghaderi A, Mahboubi M, Janizadeh R, et al. Needle-stick and medication errors in emergency nurses are due to their job stresses? A descriptive study in Kermanshah Hospitals, Iran. J Biol Today's World 2014; 3:185-188.

13. Rezaei Farsani M, Farokhpour M. Study of the rate, type and factors affecting drug errors from the perspective of nurses working in intensive care and emergency unite of educational hospitals of Shahrekord University of Medical Sciences. Dev Strategies Med Educ 2017;4:71-83 (Persian).

14. Salavati S, Hatamvand F, Tabesh H. Nurses' perspectives on causes of medication errors and non-reporting at ED. Iran J Nurs 2012; 25:72-83 (Persian).

15. Di Simone E, Giannetta N, Auddino F, Cicotto A, Grilli D, Di Muzio M. Medication errors in the emergency department: knowledge, attitude, behavior, and training needs of nurses. Indian J Crit Care Med 2018;22:346-352.

16. Mosakazemi SZ, Bastani P, Marzaleh MA, Peyravi MR. A survey on the frequency of medication errors caused due to look-alike drugs in the emergency department of the educational hospitals of Shiraz, Iran, 2016. Iran J Health Saf Environ 2019;6:1167-1174.

17. Izadpanah F, Nikfar S, Bakhshi Imcheh F, Amini M, Zargaran M. Assessment of frequency and causes of medication errors in pediatrics and emergency wards of teaching hospitals affiliated to Tehran University of Medical Sciences (24 hospitals). J Med Life 2018; 11:299-305.

18. MohammadNejad E, Ehsani SR, Salari A, Sajjadi A, HajiesmaeelPour A. Refusal in reporting medication errors from the perspective of nurses in emergency ward. J Res Dev Nurs Midwifery 2013; 10:61-68 (Persian).

19. Blaxter M. Criteria for the evaluation of qualitative research papers. Med Sociol News 1996;22:68-71. 
20. Keers RN, Williams SD, Cooke J, Ashcroft DM. Prevalence and nature of medication administration errors in health care settings: a systematic review of direct observational evidence. Ann Pharmacother 2013;47:237-256.

21. Salmasi S, Khan TM, Hong YH, Ming LC, Wong TW. Medication errors in the southeast Asian countries: a systematic review. PLoS One 2015; 10:e0136545.

22. Sherriff K, Wallis M, Burston S. Medication calculation competencies for registered nurses: a literature review. Aust J Adv Nurs 2011;28:75-83.

23. Armitage G, Newell R, Wright J. Improving the quality of drug error reporting. J Eval Clin Pract 2010;16:1189-1197.

24. Anderson S. The state of the world's pharmacy: a portrait of the pharmacy profession. J Interprof Care 2002;16:391-404.

25. Hayes C, Jackson D, Davidson PM, Power T. Medication errors in hospitals: a literature review of disruptions to nursing practice during medication administration. J Clin Nurs 2015;24:3063-3076.

26. Mansouri A, Ahmadvand A, Hadjibabaie M, Javadi M, Khoee $\mathrm{SH}$, Dastan F, et al. A review of medication errors in iran: sources, underreporting reasons and preventive measures. Iran J Pharm Res 2014;13:3-17.

27. Brown M. Medication safety issues in the emergency department. Crit Care Nurs Clin North Am 2005;17:65-69.

28. Cramer H, Pohlabeln H, Habermann M. Factors causing or influencing nursing errors as perceived by nurses: findings of a crosssectional study in German nursing homes and hospitals. J Public Health 2013;21:145-153.

29. Gholipour Baradari A, Hoseini SH, Zamani Kiasari A, Ala SH, Emami Zeydi A, Mahdavi A, Mirbakhshi SF. Effect of zinc supplement on job stress of ICU nurses. J Babol Univ Med Sci 2013; 15:38-45 (Persian).

30. Chang Y, Mark B. Effects of learning climate and registered nurse staffing on medication errors. J Nurs Adm 2011;41(7-8 Suppl): S6-S13.

31. Tang FI, Sheu SJ, Yu S, Wei IL, Chen CH. Nurses relate the contributing factors involved in medication errors. J Clin Nurs 2007; 16:447-457.

32. Sears K, O'Brien-Pallas L, Stevens B, Murphy GT. The relationship between the nursing work environment and the occurrence of reported paediatric medication administration errors: a pan Canadian study. J Pediatr Nurs 2013;28:351-356.

33. Qalehsari MQ, Khaghanizadeh M, Ebadi A. Lifelong learning strategies in nursing: a systematic review. Electron Physician 2017; 9:5541-5550.

34. Cheung KC, Bouvy ML, De Smet PA. Medication errors: the importance of safe dispensing. Br J Clin Pharmacol 2009;67:676-680.

35. Frith $\mathrm{KH}$, Anderson EF, Tseng F, Fong EA. Nurse staffing is an important strategy to prevent medication error in community hospitals. Nurs Econ 2012;30:288-294.

36. Pahlevan D, Jandaghi J, Shaeeri M, Razavi MR, Abdollahpour A, Kermani A. Classification and assessment of medication errors in the emergency unit of a hospital in Iran by SHERPA. World Fam Med 2018;16:107-112.

37. Zarif-Yeganeh M, Rastegarpanah M, Garmaroudi G, Hadjibabaie M, Sheikh Motahar Vahedi H. Incidence of medication discrepancies and its predicting factors in emergency department. Iran J Public Health 2017;46:1086-1094.

38. Winters BD, Bharmal A, Wilson RF, Zhang A, Engineer L, Defoe $\mathrm{D}$, et al. Validity of the agency for health care research and quality patient safety indicators and the centers for Medicare and Medicaid hospital-acquired conditions: a systematic review and metaanalysis. Med Care 2016;54:1105-1111.

39. Edwards S, Axe S. The 10 'R's of safe multidisciplinary drug administration. Nurs Prescr 2015;13:398-406.

40. Mirsadeghi A, Pazokian M. Barriers to reporting medication errors in Iran: a systematic review. Int J Med Rev 2015;2:317-321.

41. Amrollahi M, Khanjani N, Raadabadi M, Hosseinabadi M, Mostafaee M, Samaei S. Nurses' perspectives on the reasons behind medication errors and the barriers to error reporting. Nurs Midwifery Stud 2017;6:132-136.

42. Cloete L. Reducing medication errors in nursing practice. Nurs Stand 2015;29:50-59.

43. Maxwell SR, Webb DJ. Improving medication safety: focus on prescribers and systems. Lancet 2019;394:283-285.

44. Mieiro DB, Oliveira ÉB, Fonseca RE, Mininel VA, Zem-Mascarenhas SH, Machado RC. Strategies to minimize medication errors in emergency units: an integrative review. Rev Bras Enferm 2019;72(Supp; 1):307-314.

45. Kenawy AS, Kett V. The impact of electronic prescription on reducing medication errors in an Egyptian outpatient clinic. Int J Med Inform 2019;127:80-87.

46. Peyrovi H, Nikbakht Nasrabadi A, Valiee S. Exploration of the barriers of reporting nursing errors in intensive care units: a qualitative study. J Intensive Care Soc 2016;17:215-221. 